\title{
The Research on Programmable Control System of Lithium-Bromide Absorption Refrigerating Air Conditioner Based on the Network
}

\author{
Lunan Sun ${ }^{1}$, Lipeng $\mathrm{He}^{2}$,Zihe Yin $^{1}$, Tianxun $\mathrm{Li}^{1}$ and Shuai Guo ${ }^{3}$ \\ ${ }^{1}$ Shandong Academy of Building Research, Jinan, 250031, China \\ ${ }^{2}$ Shandong Hengxin Architectural Design co.,LTD, Jinan, 250100, China \\ ${ }^{3}$ Shanghai Advanced Research Institute, Chinese Academy of Sciences, Shanghai ,201210, China
}

\begin{abstract}
This article regard the solar lithium-bromide absorption refrigerating air conditioning system as the research object, and it was conducting adequate research of the working principle of lithium bromide absorption refrigerating machine, also it was analyzing the requirements of control system about solar energy air conditioning. Then the solar energy air conditioning control system was designed based on PLC, this system was given priority to field bus control system, and the remote monitoring is complementary, which was combining the network remote monitoring technology. So that it realized the automatic control and intelligent control of new lithium bromide absorption refrigerating air conditioning system with solar energy, also, it ensured the control system can automatically detect and adjust when the external conditions was random changing, to make air conditioning work effectively and steadily, ultimately, it has great research significance to research the air conditioning control system with solar energy.
\end{abstract}

\section{Introduction}

In the current, the global climate is becoming warmer and environmental pollution is more serious, government in countries around the world has put forward the measures and policy of saving the energy resources and reducing emissions, also actively researching the new technology to protect our earth's environment.

With the progress of the solar energy air conditioning technology, especially the application of automatic control technology and intelligent control technology is continuous improving, so that the solar energy air conditioners device will be widely used. The Solar energy air conditioning control system brings the field bus technology, network technology, virtual instrument technology and intelligent control algorithm together, not only it can reduce the labor intensity of operators, perfect working conditions, and improve the efficiency of management, but also can make the operation parameters of the unit work stability long-term within the reasonable scope,adapt to the development direction of modern industrial control system.

\section{The working principle of the lithium- bromide absorption-type refrigerating machine}

\subsection{The Working Principle of the refrigerating machine}

The single-effect lithium-bromide absorption refrigeration cycle is mainly composed of the following four cycle: hot water circulation, cold water circulation, circulation cooling water circulation and solution.

Firstly, the hot water circulation is that the water is warmed by the solar heating system, and was stored in the water tank, when the solar refrigeration systems is opening, the hot water driven pump must be opened, so the hot water have been stored in water tank was transported to generator in lithium bromide absorption refrigerating machine, to conduct heat exchange with the solution of lithium bromide and water. Secondly, the cold water circulation is the low temperature water system, which is taken place between the evaporator of lithium bromide-water chiller and the room radiators, its role is removing indoor cooling load of the room by transferring the cooling capacity in evaporator to the room. Thirdly, the cooling water circulation is extracting constant temperature water from outdoor cooling water, then transferring the cooling water to a refrigerator with the circulating pump to take away the waste heat inside the refrigerator. Finally, the solution circulation is that lithium bromide is refrigerating cold quantity inside the refrigerator.

From the above analysis, we can see that the hot water circulation is the dynamic system of lithium bromide-water absorption refrigerating machine to 
promote the operation of entire refrigeration system. The solution circulation is the key of the refrigeration cycle, it connected the other three cycle to bring four cycle into an organic whole to finish the flow process of together, it is transferring the cold capacity in the high temperature source to the indoor outdoor low temperature environment, the working principle of lithium bromide absorption refrigerating machine and the operation principle is shown in Fig. 1.

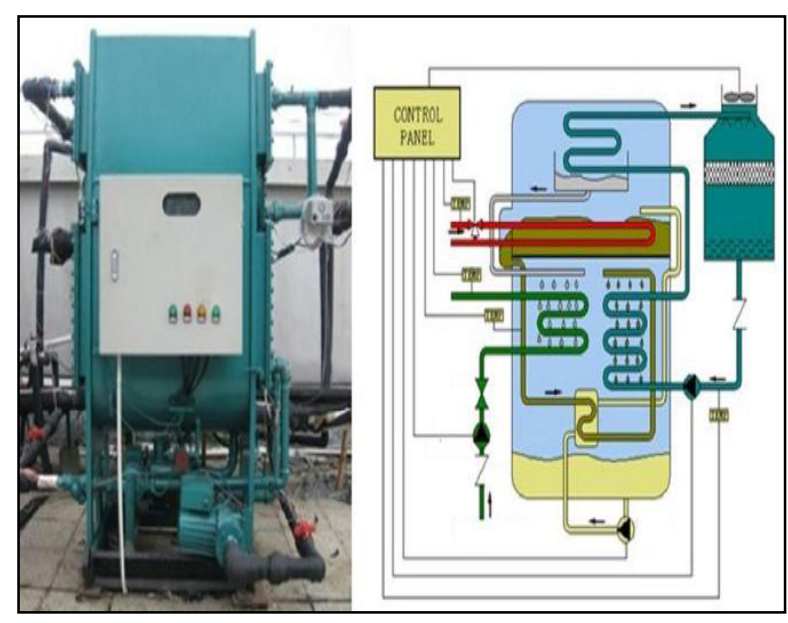

Figure 1. The working principle of lithium bromide absorption refrigerating machine and the operation principle.

\subsection{The thermodynamic model of Lithium- bromide absorption refrigerating air conditioner}

The new solar lithium-bromide absorption refrigerating air conditioner is main consist of additional the highvoltage generator, the high voltage generator, the low voltage generator, the high pressure absorber, the low pressure absorber, the condenser, the evaporator, the dilute solution storage and the cooling water storage reservoir, et al, when the water and solution is circulating flow in the equipment of all system, then, it is forming a thermodynamic model of air conditioning. And it was shown in Fig. 2.

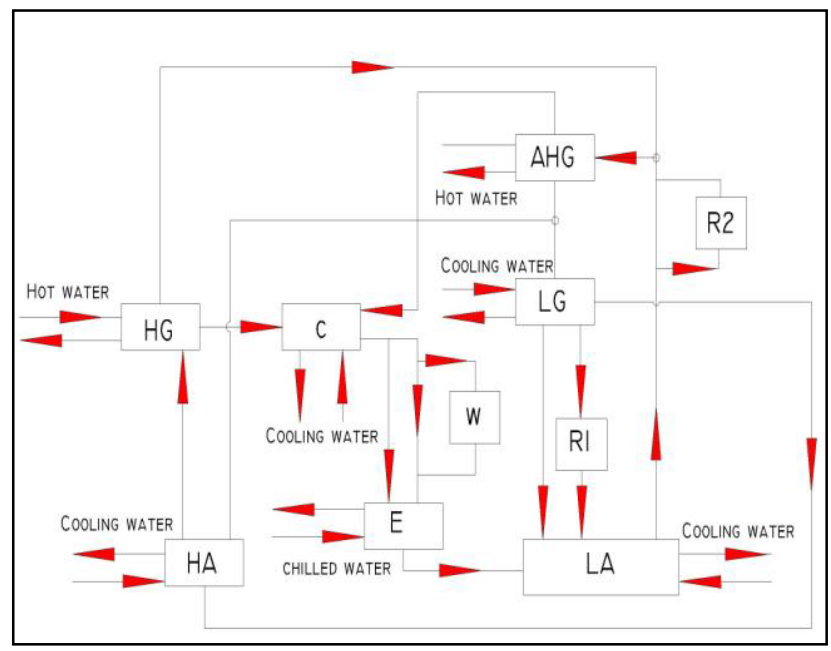

Figure 2.Thermodynamic model of air conditioning.

\section{The PLC control system of lithium bromide absorption refrigerating air conditioner}

When the system is under heating model, the thermal performance was tested and analyzed. Regarding existing problems and shortcomings of the whole system, the structure optimization analysis was conducted to seek for solutions to realize high efficiency thermal collection and application.

\subsection{The control theory of Refrigeration system}

According to the working principle of solar lithium bromide absorption refrigeration system, when it is working, the control system adjust the power switch, the circulating circulating pump, valve to realize the normal work of the four big circulation in system, the feedback data and information was mainly obtained through temperature sensor sensor, liquid level meter, flow meter, current meter, et al. The collector tubes absorb solar radiation to heat water, and hot water is transferring heat to lithium bromide solution through plate heat exchanger, according to temperature signals of the lithium bromide solution, the high and low hair three-way valve will respectively the solution in double refrigerating machine of the high or low, when the heat source water inlet temperature is higher than the switch temperature $120{ }^{\circ} \mathrm{C}\left(80 \sim 120{ }^{\circ} \mathrm{C}\right)$, the valve will switch to high temperature generator, while lower than the switch temperature $5{ }^{\circ} \mathrm{C}\left(3 \sim 20^{\circ} \mathrm{C}\right)$, the valve will switch to low temperature generator, when the heat source temperature is lower than the water chiller, the pump must stop. Only through repeating the cycle operation, it can realize the normal work of the refrigeration system.

\subsection{The programmable controller}

Programmable Logic Controller is called PLC, it is the PLC program design of the control system that the design process of writing programs by users, program design process, also it is based on the instruction and combined with the requirements of the object and field signal of that the object in processes was controlled, then by comparing the control relay number of the PLC software to draw the ladder diagram of control system, then they have begun to appreciate the immediate benefit of interoper ability between heterogeneous platforms and programming languages, using the programming language for programming, the implementation team converts this abstract, high-level design into a detailed set of design models and the pro programming language implementation. According to the requirement of the control system, the OMRON (OMRON) CJ1 PLC what was from the Japanese company was chosen to finish the control system company CJ1 series programmable controller PLC, it has so many specific functions that supporting Ultra-high speed input, releasing the task of the CPU burden by owning independent motor position control unit and the structured text function block make floating-point 
arithmetic programming more easily, so that it can meet the control demand of air-conditioning system .we can see the PLC from the following Fig. 3.

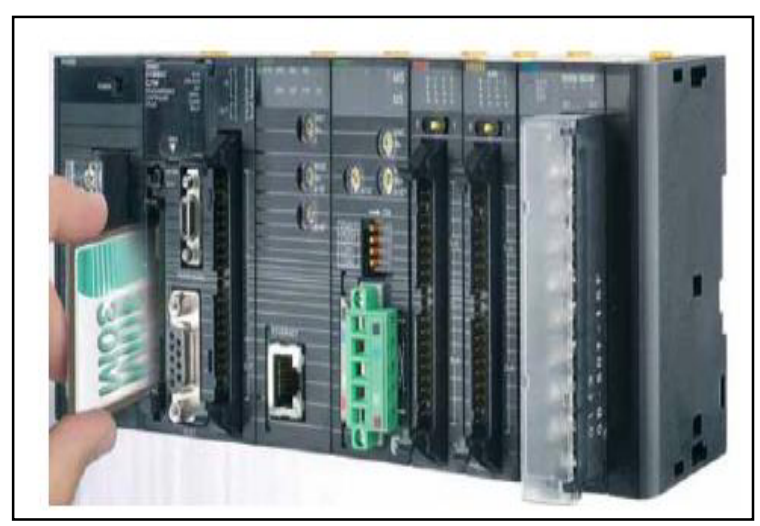

Figure. 3 The OMRON CJ1 PLC

\subsection{The electric schematic diagram of refrigeration system}

This system uses the three-phase $380 \mathrm{~V}$ as power supply, air switch is master switch, which has the overcurrent and short circuit protection features.PLC power is $24 \mathrm{~V}$, and the function of each switch button are shown in following Table 1.

Table 1.The function of the switch in control system

\begin{tabular}{|l|l|}
\hline Switch symbol & Function \\
\hline
\end{tabular}

\begin{tabular}{|c|c|}
\hline 1QA & Work start button \\
\hline $1 \mathrm{TJ}$ & The system stop button \\
\hline $1 \mathrm{HK}$ & The power switch of control circuit \\
\hline $1 \mathrm{HD}$ & The power indicator light \\
\hline 1RJ-6RJ & The heat protection relay of driving pump \\
\hline $1 \mathrm{C}-5 \mathrm{C}$ & The Circuit node switch \\
\hline $1 \mathrm{D}-6 \mathrm{D}$ & The pump motor in generator \\
\hline D01-D09 & The valve contactor \\
\hline $1 \mathrm{DL}$ & The mil malfunction lndicator Lamp \\
\hline $\mathrm{COM}$ & The output terminals \\
\hline GND & The SCT Service Circuit Terminal \\
\hline $\mathrm{X} 00-\mathrm{X} 13$ & $\begin{array}{c}\text { The input interface of normally open } \\
\text { contact }\end{array}$ \\
\hline $\mathrm{X} 14-\mathrm{X} 18$ & $\begin{array}{c}\text { The input interface of normally close } \\
\text { contact }\end{array}$ \\
\hline $\mathrm{U}$ & A phase \\
\hline $\mathrm{V}$ & B phase \\
\hline $\mathrm{W}$ & C phase \\
\hline
\end{tabular}

\subsection{The PLC electrical schematic diagram}

According to the working principle of the lithium bromide absorption refrigeration system and system components symbol, which were described above account, so that we can determine the PLC electrical schematic diagram of lithium bromide absorption refrigerating air conditioner system, which is shown in Fig. 4.

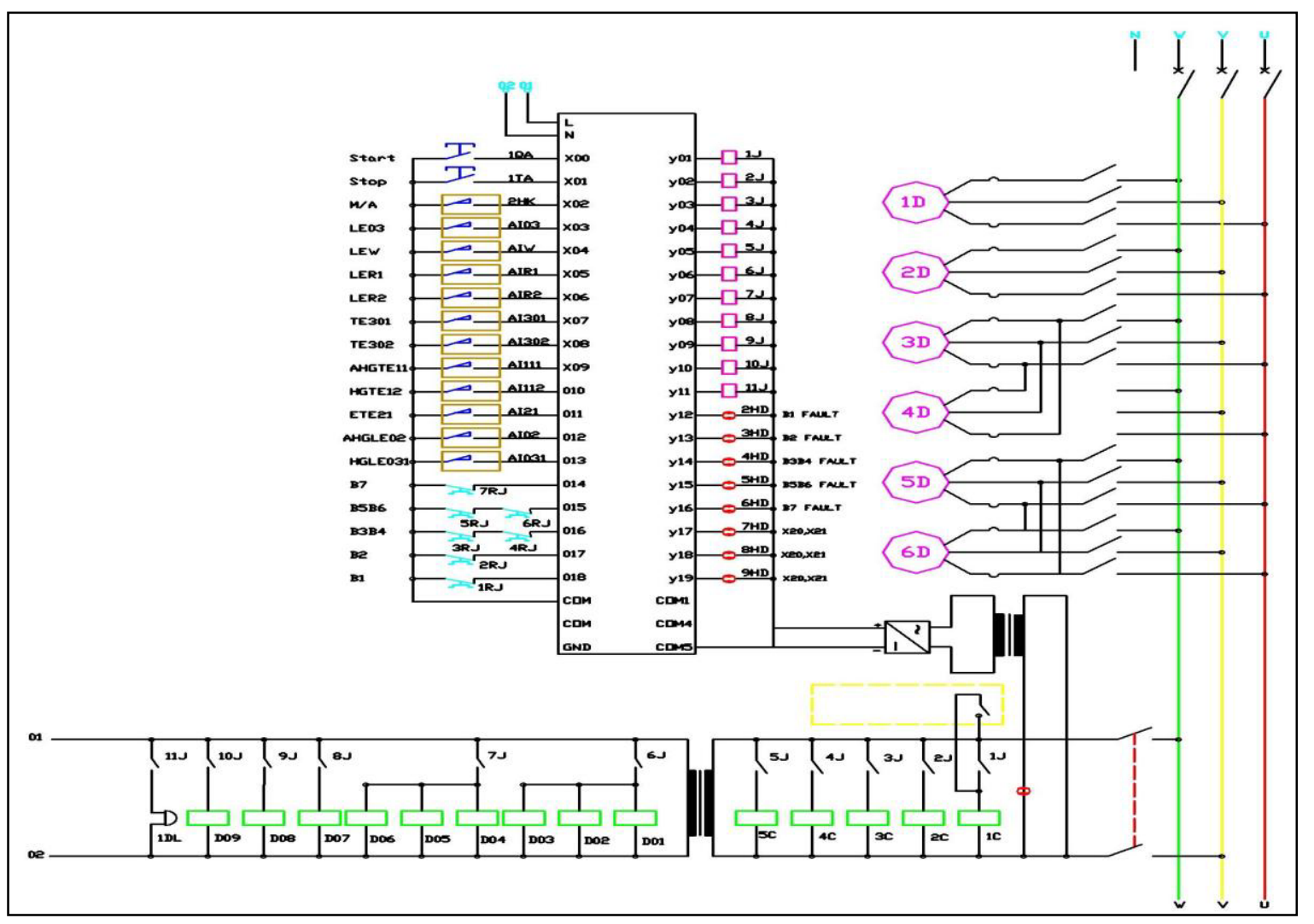

Figure 4. The PLC electrical schematic diagram of lithium bromide absorption refrigerating air conditioner system. 


\section{The field bus control system of lithium bromide absorption refrigerating air conditioner}

Introduce the working principles of solar parabolic trough concentrating system and hot water single-effect lithium bromide absorption air conditioning parabolic trough type concentrating collector, respectively. At the same time carry out the theoretical researching works on thermal performance.

A control system has already described based on network used for solar energy .The control system can not only meet the requirement of solar energy, but also be applied in other industrial control system by using the control model. The system performs the function of running control, remote monitoring, and automatic control of heating air for solar energy control system.

The solar lithium bromide absorption refrigerating air conditioner system have a great of measurement parameters and control parameters, in order to design a reasonably control system, according to the control system parameters and performance, the field bus control system mainly includes the input and output module, the computer processing module, circuit module, remote control module, the storage system, the network communication module, the principle diagram of the module are shown in Fig. 5.

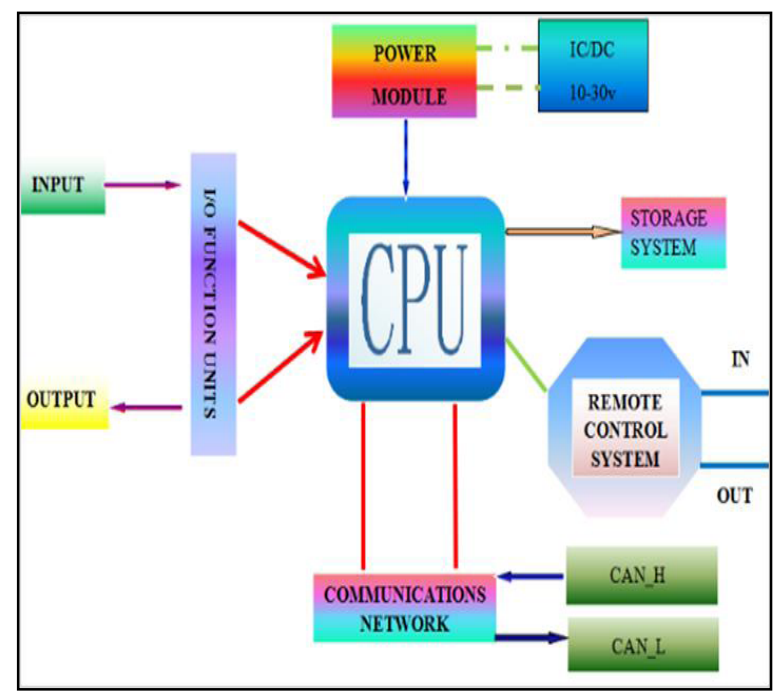

Figure 5. The field bus control system of lithium bromide absorption refrigerating air conditioner.

\section{The control performance analysis of solar energy air conditioner system}

In order to research the control performance analysis of solar energy air conditioner system, the outdoor dry bulb temperature change was regarded as a benchmark one day in a region, calculate the ourly cooling load and olar total radiation intensity in a company office conference room, the statistical results such as Table 2 .
Table 2. A company meeting room statistics of the outdoor temperature, cooling load and the intensity of solar radiation

\begin{tabular}{|c|c|c|c|}
\hline Time(h) & $\begin{array}{c}\text { The } \\
\text { Outdoor } \\
\text { temperature } \\
\left({ }^{\circ} \mathrm{C}\right)\end{array}$ & $\begin{array}{c}\text { The sun total } \\
\text { radiation } \\
\left(\mathbf{W} / \mathbf{m}^{2}\right)\end{array}$ & $\begin{array}{l}\text { Cooling } \\
\operatorname{load}(W)\end{array}$ \\
\hline 0 & 19.2 & 0.00 & 4808 \\
\hline 1 & 19.0 & 0.00 & 4735 \\
\hline 2 & 17.9 & 0.00 & 4663 \\
\hline 3 & 17.4 & 0.00 & 4612 \\
\hline 4 & 16.7 & 0.00 & 4517 \\
\hline 5 & 16.1 & 0.00 & 4539 \\
\hline 6 & 16.2 & 0.00 & 4567 \\
\hline 7 & 15.6 & 25.00 & 4735 \\
\hline 8 & 18.1 & 180.56 & 4984 \\
\hline 9 & 20.0 & 391.67 & 5221 \\
\hline 10 & 21.0 & 611.11 & 5460 \\
\hline 11 & 23.0 & 800.00 & 5668 \\
\hline 12 & 24.3 & 933.33 & 5826 \\
\hline 13 & 26.0 & 988.89 & 6273 \\
\hline 14 & 28.2 & 1000.00 & 6936 \\
\hline 15 & 28.7 & 947.22 & 7801 \\
\hline 16 & 28.8 & 825.00 & 8712 \\
\hline 17 & 28.2 & 630.56 & 9399 \\
\hline 18 & 28.2 & 405.56 & 9263 \\
\hline 19 & 27.2 & 108.33 & 5354 \\
\hline 20 & 25.2 & 19.44 & 5178 \\
\hline 21 & 22.7 & 0.00 & 5056 \\
\hline 22 & 21.7 & 0.00 & 4932 \\
\hline 23 & 21.0 & 0.00 & 4910 \\
\hline
\end{tabular}

\section{Conclusion}

In this paper, it focuses on the solution for the remote control system in solar energy lithium bromide absorption refrigerating air conditioner, and it based on field bus technology, this design scheme not only can effectively realize the function of the whole solar energy air conditioner operation system, but also, it can realize monitoring across the region to provide a more convenient and more efficient system solutions for staff through the network data interaction. It is this way that conducting a monitoring system based on networks can make the information transmission, monitoring, management, and other functions integrated into a modularization system to realize integration of management and control, all in all, it has great research significance to research the air conditioning control system with solar energy.

\section{References}

1. Zhang Yunjuan. Research on the Characteristic and Auto-control System of a Novel Solar Absorption Air-conditioning with an Energy Storage Unit[D].Wuhan: Huazhong University of Science \& Technology.2005.4

2. M. Eck, E. Zarza, M. Eickhoff, et al. Applied research concerning the direct steam generation in parabolic troughs [J]. Solar Energy, 2003, 74: 341 351. 
3. Xiande Fang, Baoyi Chen, Zhuyi Zheng. A study of the influence of solar radiation on the thermal performance of evaporators of heat pump system. Applied Thermal Engineering. 2003, 23, pp. 15511557.

4. Inci Turk Togrul,Dursun Pehl Bvan,Cevdet Akosman. Development and testing of a solar airheater with conical concentrator. Renewable Energy.2004, 29. pp. 263-275.

5. A.Yattara, Y. Zhu, M. Mosa Ali. Comparison between solar single-effect and single-effect doublelift absorption machines. Applied Thermal Engineering.2003, Vol. 23, pp. 1981-1992.

6. Afif. Akel. Hasan, D. Yogi. Goswami, Sanjay Vijayaraghavan. First and second law analysis of a new power and refrigeration thermodynamic cycle using a solar heat source. Solar Energy. 2002, 73(5), pp. 385-393.
7. A. Syed, M. Izquierdo, P. Rodriguez, et al. A novel experimental investigation of a solar cooling system in Madrid [J]. International Journal of Refrigeration, 2005, 28:859-871.

8. W.S.Duff,R.Winston,J.J.Gallagher, t,al. erformance of the Sacramento demonstration ICPC collector and double effect chiller [J]. Solar Energy, 2004, 76:175-180.

9. T. Lin, X.M. Sui. Design of air conditioning system for an apartment hotel in Shanghai. Heating Ventilating \& Air Conditioning, 38(6), (2008), pp. 98-102.

10. Doosam Song, Taeyeon Kim, Suwon Song, Suckho Hwang, Seung-Bok Leigh. Performance evaluation of a radiant floor cooling system integrated with dehumidified ventilation. Applied Thermal Engineering, 28, August 2008, pp. 12991311. 